\title{
On the Importance of Combining the Theoretical Teaching and Practical Teaching of College Sailing Club Courses-Taking Qingdao University of Science and Technology as an Example
}

\author{
Yong-quan Jin $^{1}$ \\ ${ }^{1}$ Qingdao University of Science and Technology, Qingdao, China \\ Correspondence: Yong-quan Jin. E-mail: jyqff@163.com
}

Received: October 20, 2018

Accepted: November 28, 2018

Online Published: January 30, 2019

doi:10.5539/ass.v15n2p147

URL: https://doi.org/10.5539/ass.v15n2p147

\begin{abstract}
The 18th National Congress of the Communist Party of China put forward the maritime power strategy. College students shoulder the heavy responsibility of building a maritime power, and they can get close to the ocean and appreciate the charm of the sea through participating in sailing. In recent years, with the rapid development of sailing in China, more and more colleges and universities have begun to participate in the sailing. For example, Xiamen University on behalf of China to participate in the World University Sailing Championships, and Qingdao University of Science and Technology on behalf of China to participate in the Russian St. Petersburg University Regatta. More and more sailing teams of universities went abroad to the world. In 2017, the China University Student Sailing Championship attracted more than 30 colleges and universities from all over the country. There are sailing courses in the universities that performance well in sailing races, such as Xiamen University, Qingdao University of Science and Technology, Dalian Maritime University. These courses are loved by many students, and the sport is especially appealing to students who like challenges, brainstorm and enjoy good physical constitution. Sailing is a combination of intelligence and physical strength. Theory and practical teaching are both very important in teaching. If the teacher combines theory and practical teaching in the teaching process, then the students will have a more solid grasp of the learning content in the sailing course, and their learning process will be more secure.
\end{abstract}

Keywords: sailing, Sailing Club courses, theoretical and practical teaching

\section{Introduction}

\subsection{Introduction to Sailing}

Sailing, as one of the water sports, is a sport combining competition, entertainment and exploration, which relies on the natural wind power for sail and is driven by human (Editorial Board for Textbooks of "Sailing into the Campus Program", 2013). Sailing is a perfect combination of wind, water, people and boat. It is a join of leisure, competition, fitness and entertainment, the match of culture, tourism, sports and the sea, and the harmony of man and nature. Sailing originated in Europe, and its history can be traced back to ancient times. China boasts a long history of maritime civilization. However, the beginning of Chinese sailing industry was that after the founding of the People's Republic of China, and sailing was introduced into China in the mid-1950s. With the success of the 2008 Beijing Olympic Games Qingdao Olympic Regatta, Chinese sailing has developed rapidly in the past decade. Xu Lijia, a Chinese sailor, won the championship in 2012 London Olympic Games. China's Dongfeng team won the Volvo global sailing competition in 2018. Qingdao Station has been the stop for the Clipper Round the World Yacht Race for ten consecutive years.

\subsection{The Development of Qingdao Sailing}

Qingdao was the city in China where sailing began. It was first introduced to Qingdao by people from western countries. According to records, there were sailing competitions in Qingdao in 1904. As an Olympic City, Qingdao has always been the leading city of Chinese sailing, and is known as the Sailing City. Since 2006, "sailing into the campus" has been fully opened in primary and secondary schools in Qingdao. By 2018 there are 138 sailing schools in the whole city with a total of more than 30,000 students (Editorial Board for Textbooks of "Sailing into the Campus Program", 2013). 


\subsection{The Development of Sailing in Qingdao University of Science and Technology}

In 2006, the "Sailing into the Campus Program" was fully opened in Qingdao. Qingdao University of Science and Technology was the first batch of sailing specialized schools. In 2012, Qingdao government established 32 demonstration schools for sailing sports from those sailing specialized schools, and Qingdao University of Science and Technology is one of them. Qingdao University of Science and Technology boasts a Sailing Team which was established in 2008 and a Sailing Fan Association which was established in 2010. The school sailing club courses were set up in 2013. After five years of curriculum construction, a more complete sailing course teaching system has been formed. The courses were given according to a complete teaching calendar and a teaching outline by professional teachers.

\section{Research Method}

\subsection{Research Object}

This paper takes the sailing courses of Qingdao University of Science and Technology Sailing Club as the research object.

\subsection{Research Contents}

The Importance of Theoretical teaching and Practical teaching of the sailing courses of the Sailing Club; the teaching effect of combining Theoretical with Practical teaching in Sailing Club courses

\section{Discussion and Analysis}

\subsection{Development of Sports Club Curriculum in Colleges and Universities in China}

With the deepening of college curriculum reform, one of the development trends of College Physical Education Curriculum in China is to carry out physical education in the form of clubs. In order to help students to develop a lifelong habit of exercise, the teaching mode of sports club is in line with targets of talent cultivation in colleges and universities, combining with the needs of college students for physical education. For students, this teaching mode contributes to master some skills of long-term physical exercise, and gives full play to individual sports talents, interests and hobbies (Bei, 2006). It is students-centered; to focus on the teaching process; to enable students to choose their own learning content according to their own characteristics and interests, to meet the needs of their personality development, and at the same time to give full play to the professional expertise of teachers; to make reasonable and effective use of teaching facilities; to find excellent students in sports specialty; to improve the colleges' level of athletics campaign (Wen, 2004). In the past, the teaching forms of physical education classes in colleges and universities were single, generally led by teachers. At that time, students were passive in learning, and they were not interested in the sports programs that teachers explain, and they were unable to exert their subjective initiative as a result. The diversity of teaching in the form of clubs allows students to participate in sports that are of interest to them. Teachers and students ask each other questions in a relaxed and pleasant environment and solve problems together, and students can better exert their subjective initiative. Therefore, students can gradually form life-long sports awareness.

\subsection{Development of the Teaching of Sports Clubs in Qingdao University of Science and Technology}

Qingdao University of Science and Technology Sports Club's existing projects include: track and field, sailing, martial arts, basketball, football, volleyball, Sanda (free combat), Taekwondo, aerobics and many other sports items. Students like the sports club's curriculum very much, and they can use their spare time to participate in their favorite sports items. All of those club teachers boast professional skills. The students have greatly improved their skills and tactics after guided by these teachers. Sailing is the earliest sports club project of Qingdao University of Science and Technology. After years of development, it has formed a relatively complete teaching system. There are many common students who have realized their nautical dreams by participating in the sailing club and have experienced themselves through the baptism of the navigation. The members selected through the sailing courses formed the sailing team of Qingdao University of Science and Technology. The team members have undergone professional training and have achieved many successes in international and domestic sailing events in recent years.

\subsection{Importance of Combining the Theoretical teaching and Practical teaching of College Sailing Club Courses}

\subsubsection{Importance of the Theoretical teaching of College Sailing Club Courses}

In the college education system in developed countries, sports theoretical teaching and practical teaching are equally important. The teaching of theoretical courses in college physical education courses accounts for about $40 \%$ of the total courses. However, the teaching of physical education courses in Chinese universities is practical teaching-oriented, and the proportion of theoretical courses in the total courses is very low, ignoring theoretical 
teaching. The sailing in Chinese colleges and universities started relatively late, and there is no precedent for reference. The teaching of the sailing club of Qingdao University of Science and Technology has been improving the curriculum construction through several years of exploration combining the characteristics of the sailing project. The teaching practice of the club sailing course proves that theoretical teaching is very important in sailing teaching. As sailing is carried out on the water, sailing teaching requires a combination of different kinds of knowledge. First of all, students should learn the basic theoretical knowledge of sailing, such as: knowledge of the origin and development of sailing, weather and marine environment, sailing safety and lifesaving, the navigation schematics, sailing tactics and strategies, sailing emergency measures and sailing competition rules, etc.. Through systematic learning of theoretical knowledge, students will pave the way for future water courses, and better ensure the efficiency of water practice and safety.

\subsubsection{Importance of the Practical Teaching of College Sailing Club Courses}

Sailing is carried out on the water, and the situation at sea is quite complicated, so the participants in the sailing club must first learn how to swim and they should swim for a longer distance. The first practical lesson is to test the students' swimming skills. The sea conditions and weather conditions are different each time. This is a process of accumulating experience through practical lessons. Sailing practical courses are often carried out under different winds and sea conditions. When driving a sailboat, students should not only learn to control the course and speed, but also ensure that the sailboat does not overturn. This requires the students to try their best to maintain the balance of the sailboat. In addition, students need to have good physical fitness to adapt to the long-term sea turbulence; at the same time they have to be clear-headed to grasp the surrounding environment, water flow rate, flow direction, and changes in wind direction and wind speed. And also they should learn to inspect and organize the equipment on board, especially to learn to adjust the sail type to suit the maximum lift. All of the above require students to practice repeatedly in the sailing courses. Engaging in sailing enables people to enhance physical fitness, and temper one's willpower, especially in the unpredictable sea to meet the wind and waves, can train the students to develop the fighting spirit.

\subsection{Features of Combining the Theoretical Teaching and Practical Teaching of College Sailing Club Courses}

\subsubsection{Pertinence}

The sailing course offered by Qingdao University of Science and Technology has a strong pertinence for the teaching content. The teacher will conduct two theoretical classes at the beginning of the course. Students can visualize sailing by watching a variety of videos about sailing and learn to assemble sailboats in later practice classes by learning the frequently-used knots of sailboat. Students will fully practice in the limited time of the practical class, for example, they practice sailing simulation driving, learn how to deal with sailing accidents, and simulate to save people who were drowned. In the theoretical class, the teacher will explain and analyze the technical problems that most students have in the previous practical class, and teach more effective technical skills, so that students can closely integrate theory and practice.

\subsubsection{Diversity}

The combination of theory and practice can enrich and diversify the theoretical or practical lessons. The short-term theoretical course provides students with an understanding of the basic theory of sailing and the basic technical movements of sailing. Later, in the physical training class, the students practice to sail on the water. In practical class, students may have some wrong technical actions and misunderstanding of wind and water flow. Then, the teacher will give a targeted explanation and simulation operation in the next theoretical class to correct the students' wrong actions. In this way, students will learn sailing more effectively. In the past, students who participated in traditional physical education classes are required to repeat preparatory activities and basic technical review, which made students' interest in college physical education gradually weakened. If the teacher continuously teaches the theoretical class, the physical education class will become boring. The combination of practical courses and theoretical courses changes the old-fashioned teaching concepts, innovates teaching methods, enriches the content of the lessons, and lay a good foundation for improving students' interest in sailing.

\section{Conclusion}

(1) The sailing club curriculum of Qingdao University of Science and Technology combining of the theory and practical teaching is gradually developing. The problem of "attaches importance to the practical teaching, despises the theory" is gradually solved in the course construction, but a scientific and suitable curriculum system has not yet been formed.

(2) Participants involved in sailing need to have good physical quality conditions, and also must have a high 
cultural quality. They should master the multidisciplinary knowledge of aerodynamics, physical mechanics, meteorology, hydrology and so on. It is important to combine the theoretical teaching and practical teaching of sailing clubs. With the premise of mastering basic theories and mastering basic driving skills through simulated driving, students can better ensure their safety when practical teaching on water. In addition, students' learning effect will be better.

(3) Combining the Theoretical teaching and Practical teaching of College Sailing Club Courses has significantly improved students' interest in sports courses and obviously their attitudes become more positive.

\section{References}

Bei, L. (2006). The important role of college sports clubs. Liaoning Education Research, (10), 107. Retrieved from http://lib.cqvip.com/qk/23214473.html-1002-8609

Editorial Board for Textbooks of "Sailing into the Campus Program". (2013). Knowledge of Sailing Boats. Qingdao, QD: Qingdao Publishing House

Li, Z. H. (2011). Feasibility Study on Sports Courses Combining Theroy and Practical teaching in Colleges. The journal science Tribune, (22), 215-216. Retrieved from http://lib.cqvip.com/qk/38945433.html-1674-6813

Wen, S, P. (2004). Research on the Teaching Mode of College Sports Clubs. Journal of Sport History and Culture, (10), 56-57. Retrieved from http://lib.cqvip.com/qk/11065660.html-1671-1572

Yi, C. Y., Wang, Y. Z., \& Deng, Z. L. (2005). Application of PE Teaching Model in Physical Education of Colleges. Journal of Shandong Insitute of Physical Education and Sports, 21(1), 86-87. Retrieved from http://lib.cqvip.com/qk/15943211.html-1006-2076

\section{Copyrights}

Copyright for this article is retained by the author(s), with first publication rights granted to the journal.

This is an open-access article distributed under the terms and conditions of the Creative Commons Attribution license (http://creativecommons.org/licenses/by/4.0/). 